\title{
Correction to: Miklós-Manickam-Singhi conjectures on partial geometries
}

\author{
Ferdinand Ihringer ${ }^{1} \cdot$ Karen Meagher $^{2}$ \\ Published online: 5 February 2019 \\ (c) Springer Science+Business Media, LLC, part of Springer Nature 2019
}

\section{Correction to: Des. Codes Cryptogr. (2018) 86:1311-1327 https://doi.org/10.1007/s10623-017-0397-6}

The original version of this article contains an error. The authors incorrectly quoted Manickam-Miklós-Singhi (MMS) conjecture as "Miklós-Manickam-Singhi". The correct term for the conjecture is Manickam-Miklós-Singhi.

Publisher's Note Springer Nature remains neutral with regard to jurisdictional claims in published maps and institutional affiliations.

The original article can be found online at https://doi.org/10.1007/s10623-017-0397-6.

$凶$ Ferdinand Ihringer

ferdinand.ihringer@gmail.com

Karen Meagher

karen.meagher@uregina.ca

1 Einstein Institute of Mathematics, The Hebrew University of Jerusalem, Givat Ram, 9190401 Jerusalem, Israel

2 Department of Mathematics and Statistics, University of Regina, 3737 Wascana Parkway, Regina, SK S4S 0A4, Canada 